\title{
EFFECT OF TEMPERATURE ON THE ELECTRICAL CONDUCTANCE OF HYDROGEN CHLORIDE IN DIMETHYLSULPHOXIDE*
}

\author{
J. A. Bolzan and A. J. Arvifa \\ Instituto de Investigaciones, División Electroquímica, Facultad de Ciencias \\ Exactas, Universidad de La Plata, La Plata, Argentina
}

\begin{abstract}
The electrical conductance of solutions of hydrogen chloride in dimethylsulphoxide at temperatures from 25 to $45^{\circ} \mathrm{C}$ has been studied. Results have been interpreted with the Fuoss theory for associated 1-1 type electrolytes. Values of the association constant $K_{A}$ and the $J$ parameter have been computed at each temperature. The temperature dependence of the molar conductance is inferred from the theoretical equation and related to the temperature dependence of viscosity.
\end{abstract}

Résumé-La conductance électrique des solutions de chlorure d'hydrogène dans le diméthylsulfoxyde à des températures de 25 a $45^{\circ} \mathrm{C}$ a été étudiée. Les résultats ont été inteprétés par la théorie de Fuoss pour des electrolytes associées du type 1-1. Les valeurs de la constante d'association $K_{\mathrm{A}}$ et du paramètre $J$ ont été calculées à chaque température. La dépendance de la conductivité molare avec la température est déduite de l'équation théorique et référée a la dépendance de la viscosité avec la température.

Zusammenfassung-Die elektrische Leitfähigkeit der Lösungen von Chlorwasserstoff in Dimethylsulfoxyd bei Temperaturen von 25 bis $45^{\circ} \mathrm{C}$ wurde studiert. Die Ergebnisse wurden mittels der Theorie von Fuoss für Electrolyte des 1-1 assoziarten Typs gedeutet. Die Werte der Assoziationskonstante $K_{A}$ und der Parameter $J$ wurden für jede Temperatur berechnet. Die Temperaturabhängigkeit des Molarenkonduktanz ist von der theoretischen Gleichung abgeleitet und auf die Temperaturabhängigkeit der Viskosität bezogen.

\section{INTRODUCTION}

IN EARLIER papers the electrical conductance of solutions of hydrogen chloride in DMSO has been studied at $25^{\circ} \mathrm{C.}{ }^{1.2}$ It has been observed that $\mathrm{HCl}$ behaves in this solvent as a markedly associated 1-1 type electrolyte, its association constant $K_{\mathbf{A}}$ being $115.7 \mathrm{l} / \mathrm{mole}$. This behaviour is dissimilar with that of other electrolytes of the same type in DMSO, 3 which are completely dissociated strong electrolytes over a rather large range of concentration. It is then of interest to extend previous work on this matter to other temperature and viscosity ranges, to discover the energetic peculiarities of the mechanism of electrical conduction.

\section{EXPERIMENTAL TECHNIQUE}

Experimental techniques for the measurement of the electrical conductance and viscosity, purification of the solvent and preparation of solutions have been described elsewhere. ${ }^{2.4}$ Experiments were made in the range $10^{-1}-10^{-5} \mathrm{M}$, at temperatures from $25^{\circ}$ to $45^{\circ} \mathrm{C}$.

\section{RESULTS}

The experimental results of the electrical conductance are assembled in Tables 1-5. $\kappa$ is the specific conductance and $C$ the molar concentration. At each temperature, concentrations were corrected for density changes and the molar conductances $\Lambda$ were calculated accordingly.

The dependence of the molar conductance with concentration is shown in Fig. 1, where it is plotted vs $C^{1 / 2}$ at different temperatures. Figure 2 shows results of viscosity measurements, in a plot of the viscosity coefficient $\eta v s C^{1 / 2}$, for each temperature.

* Manuscript received 27 March 1969. 
Table 1. Conductance data at $25^{\circ} \mathrm{C}$

\begin{tabular}{|c|c|c|c|c|c|}
\hline $\begin{array}{c}C \\
\mathbf{M}\end{array}$ & $\underset{\text { int.ohm }}{\kappa-1 / \mathrm{cm}^{-1}}$ & $\begin{array}{c}\Lambda \\
\text { int.ohm-1. } \\
\mathrm{cm}^{2} . \mathrm{mol}^{-1}\end{array}$ & $\gamma$ & $\begin{array}{l}\eta \times 10^{2} \\
\mathrm{~g} / \mathrm{cm} \text { per s }\end{array}$ & $\begin{array}{c}\Lambda \eta \\
\mathrm{g} \mathrm{cm} \text { int. } \\
\mathrm{ohm}^{-1} \cdot \mathrm{s}^{-1} \\
\mathrm{~mole}^{-1}\end{array}$ \\
\hline $\begin{array}{l}5.383 \times 10^{-2} \\
4.306 \times 10^{-2} \\
2.153 \times 10^{-2} \\
1.724 \times 10^{-2} \\
1.036 \times 10^{-2} \\
8.305 \times 10^{-2} \\
6.648 \times 10^{-2} \\
4.297 \times 10^{-3} \\
3.327 \times 10^{-3} \\
1.664 \times 10^{-8} \\
8.585 \times 10^{-4} \\
8.337 \times 10^{-4} \\
4.179 \times 10^{-4} \\
1.716 \times 10^{-4} \\
8.350 \times 10^{-5}\end{array}$ & $\begin{array}{l}7.294 \times 10^{-4} \\
6.317 \times 10^{-4} \\
3.972 \times 10^{-4} \\
3.348 \times 10^{-4} \\
2.373 \times 10^{-4} \\
1.987 \times 10^{-4} \\
1.724 \times 10^{-4} \\
1.160 \times 10^{-4} \\
9.835 \times 10^{-8} \\
5.411 \times 10^{-8} \\
2.927 \times 10^{-5} \\
2.844 \times 10^{-5} \\
1.507 \times 10^{-5} \\
6.349 \times 10^{-6} \\
3.154 \times 10^{-8}\end{array}$ & $\begin{array}{l}13 \cdot 55 \\
14 \cdot 67 \\
18 \cdot 45 \\
19 \cdot 42 \\
22 \cdot 91 \\
23 \cdot 93 \\
25 \cdot 93 \\
27 \cdot 00 \\
29 \cdot 56 \\
32 \cdot 52 \\
34 \cdot 10 \\
34 \cdot 11 \\
36 \cdot 06 \\
37 \cdot 00 \\
37 \cdot 77\end{array}$ & $\begin{array}{l}0.450 \\
0.477 \\
0.568 \\
0.589 \\
0.675 \\
0.697 \\
0.749 \\
0.765 \\
0.830 \\
0.896 \\
0.925 \\
0.925 \\
0.968 \\
0.983 \\
0.998\end{array}$ & $\begin{array}{l}2 \cdot 085 \\
2 \cdot 080 \\
2 \cdot 061 \\
2 \cdot 053 \\
2 \cdot 045 \\
2 \cdot 042 \\
2 \cdot 038 \\
2 \cdot 032 \\
2 \cdot 030 \\
2 \cdot 027 \\
2 \cdot 023 \\
2 \cdot 022 \\
2 \cdot 020 \\
2 \cdot 020 \\
2 \cdot 018\end{array}$ & $\begin{array}{l}0.283 \\
0.305 \\
0.380 \\
0.399 \\
0.469 \\
0.489 \\
0.528 \\
0.549 \\
0.600 \\
0.659 \\
0.690 \\
0.690 \\
0.728 \\
0.747 \\
0.762\end{array}$ \\
\hline
\end{tabular}

The molar conductance increases monotonously with decreasing concentration at all temperatures, as already reported for $25^{\circ} \mathrm{C},{ }^{2}$ while at constant concentration it increases with the temperature, following as a first approximation an Arrhenius equation. On this basis average values of the experimental activation energy for conductances, $\Delta H_{\Lambda}{ }^{*}$, are calculated. These values lie between $3.2 \pm 0.3$ and $2.4 \pm 0.3$ $\mathrm{Kcal} /$ mole. $\Delta H_{\Lambda}{ }^{*}$ tends to decrease with increasing concentration, as shown in Fig. 3. Viscosity also decreases with concentration and temperature. Figure 4 shows these results. In a plot of $\log \eta v s 1 / T$ slightly bent curves are obtained for all concentrations, but the average experimental activation energy for viscosity, $\Delta H_{\eta}{ }^{*}$, is $3.0 \pm 0.1 \mathrm{kcal} / \mathrm{mole}$, for the pure solvent and for all the range of concentrations studied, can be calculated.

These results indicate that at least at infinite dilution, where $\Delta H_{\Lambda}{ }^{*}$ and $\Delta H_{\eta}{ }^{*}$

Tabee 2. Conductance data at $30^{\circ} \mathrm{C}$

\begin{tabular}{|c|c|c|c|}
\hline $\begin{array}{l}C \\
\mathbf{M}\end{array}$ & $\stackrel{\kappa}{\kappa}$ & 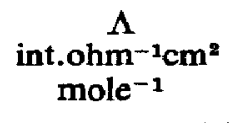 & $\gamma$ \\
\hline $\begin{array}{l}5.361 \times 10^{-2} \\
4.288 \times 10^{-8} \\
2.144 \times 10^{-8} \\
1.717 \times 10^{-2} \\
1.032 \times 10^{-2} \\
8.271 \times 10^{-8} \\
6.621 \times 10^{-8} \\
4.279 \times 10^{-8} \\
3.313 \times 10^{-8} \\
1.657 \times 10^{-8} \\
8.550 \times 10^{-4} \\
8.303 \times 10^{-4} \\
4.162 \times 10^{-4} \\
1.709 \times 10^{-4} \\
2.316 \times 10^{-5} \\
1.663 \times 10^{-5}\end{array}$ & $\begin{array}{l}7.885 \times 10^{-4} \\
6.820 \times 10^{-4} \\
4.297 \times 10^{-4} \\
3.632 \times 10^{-4} \\
2.572 \times 10^{-4} \\
2.163 \times 10^{-4} \\
1.876 \times 10^{-4} \\
1.265 \times 10^{-4} \\
1.074 \times 10^{-4} \\
5.866 \times 10^{-5} \\
3.204 \times 10^{-6} \\
3.123 \times 10^{-5} \\
1.655 \times 10^{-5} \\
7.068 \times 10^{-6} \\
3.507 \times 10^{-6} \\
7.309 \times 10^{-7}\end{array}$ & $\begin{array}{l}14 \cdot 71 \\
15 \cdot 90 \\
20 \cdot 04 \\
21 \cdot 15 \\
24 \cdot 92 \\
26 \cdot 15 \\
28 \cdot 33 \\
29 \cdot 56 \\
32 \cdot 42 \\
35 \cdot 40 \\
37 \cdot 47 \\
37 \cdot 61 \\
39 \cdot 76 \\
41 \cdot 36 \\
42 \cdot 17 \\
43 \cdot 95\end{array}$ & $\begin{array}{l}0.445 \\
0.470 \\
0.561 \\
0.584 \\
0.670 \\
0.695 \\
0.747 \\
0.764 \\
0.843 \\
0.890 \\
0.929 \\
0.932 \\
0.974\end{array}$ \\
\hline
\end{tabular}


Table 3. Conductance data at $35^{\circ} \mathrm{C}$

\begin{tabular}{|c|c|c|c|}
\hline $\begin{array}{l}C \\
\mathbf{M}\end{array}$ & int.ohm ${ }^{-1} \mathrm{~cm}^{-1}$ & $\underset{\substack{\text { int.ohm-1 } \mathrm{cm}^{2} \\
\mathrm{~mole}^{-1}}}{\Lambda}$ & $\gamma$ \\
\hline $\begin{array}{l}5.339 \times 10^{-2} \\
4.271 \times 10^{-2} \\
2.135 \times 10^{-1} \\
1.710 \times 10^{-2} \\
1.027 \times 10^{-1} \\
8.237 \times 10^{-3} \\
6.593 \times 10^{-3} \\
4.262 \times 10^{-8} \\
3.300 \times 10^{-8} \\
1.650 \times 10^{-8} \\
8.514 \times 10^{-4} \\
8.268 \times 10^{-4} \\
4.145 \times 10^{-4} \\
1.702 \times 10^{-8} \\
8.281 \times 10^{-5} \\
1.656 \times 10^{-3}\end{array}$ & $\begin{array}{l}8.436 \times 10^{-4} \\
7.307 \times 10^{-4} \\
4.602 \times 10^{-4} \\
3.910 \times 10^{-4} \\
2.780 \times 10^{-4} \\
2.336 \times 10^{-4} \\
2.012 \times 10^{-4} \\
1.373 \times 10^{-4} \\
1.162 \times 10^{-4} \\
6.371 \times 10^{-5} \\
3.491 \times 10^{-5} \\
3.410 \times 10^{-5} \\
1.795 \times 10^{-6} \\
7.770 \times 10^{-6} \\
3.898 \times 10^{-4} \\
7.979 \times 10^{-7}\end{array}$ & $\begin{array}{l}15 \cdot 80 \\
17 \cdot 11 \\
21 \cdot 56 \\
22 \cdot 87 \\
27 \cdot 07 \\
28 \cdot 36 \\
30 \cdot 52 \\
32 \cdot 21 \\
35 \cdot 21 \\
38 \cdot 61 \\
41 \cdot 00 \\
41 \cdot 24 \\
43 \cdot 31 \\
45 \cdot 65 \\
47 \cdot 07 \\
48 \cdot 18\end{array}$ & $\begin{array}{l}0.436 \\
0.466 \\
0.546 \\
0.570 \\
0.655 \\
0.678 \\
0.726 \\
0.747 \\
0.810 \\
0.868 \\
0.907 \\
0.912 \\
0.963 \\
0.988\end{array}$ \\
\hline
\end{tabular}

have practically the same absolute value, the Walden product $\Lambda_{0} \eta_{0}$, where $\Lambda_{0}$ is the limiting molar conductance and $\eta_{0}$ the solvent viscosity, should be temperatureindependent as observed in Table 6 . On the contrary, from Table 1 it is seen that the product $\Lambda \eta$, at constant temperature, depends on concentration. This shows that the mechanisms of the above processes are differently affected by ionic interactions, which must play an increasing role at higher concentrations, particularly in the mechanism of electrical conduction.

\section{DISCUSSION}

On the basis of the interpretation advanced in a previous paper, ${ }^{2}$ the results are now discussed with the Fuoss theory for associated 1-1 type electrolytes. ${ }^{5}$ The following general equation applies in the range from 25 to $45^{\circ} \mathrm{C}$,

$$
\Lambda_{\eta}=\Lambda_{0}-S(C \gamma)^{1 / 2}+E C \gamma \log (C \gamma)+J C \gamma-K_{\Lambda} C \gamma f^{2} \Lambda_{\eta}
$$

table 4. Conductance data at $40^{\circ} \mathrm{C}$

\begin{tabular}{|c|c|c|c|}
\hline $\begin{array}{l}C \\
\mathbf{M}\end{array}$ & $\stackrel{\kappa}{\kappa}$ int.ohm ${ }^{-1} \mathrm{~cm}$ & $\underset{\substack{\Lambda \\
\text { int.ohm }}}{\mathrm{mole}^{-1}}$ & $\gamma$ \\
\hline $5.317 \times 10^{-2}$ & $8.919 \times 10^{-4}$ & $16 \cdot 77$ & 0.425 \\
\hline $4.253 \times 10^{-2}$ & $7.778 \times 10^{-4}$ & $18 \cdot 29$ & 0.459 \\
\hline $2.126 \times 10^{-2}$ & $4.923 \times 10^{-4}$ & $23 \cdot 16$ & 0.543 \\
\hline $1.703 \times 10^{-2}$ & $4.183 \times 10^{-4}$ & $24 \cdot 56$ & 0.567 \\
\hline $1.023 \times 10^{-2}$ & $2.978 \times 10^{-4}$ & $29 \cdot 11$ & 0.654 \\
\hline $8.203 \times 10^{-a}$ & $2.506 \times 10^{-4}$ & $30 \cdot 55$ & 0.678 \\
\hline $6.566 \times 10^{-3}$ & $2.170 \times 10^{-4}$ & 33.05 & 0.727 \\
\hline $4.244 \times 10^{-3}$ & $1.476 \times 10^{-4}$ & $34 \cdot 78$ & 0.749 \\
\hline $3.286 \times 10^{-8}$ & $1.249 \times 10^{-4}$ & $38 \cdot 01$ & 0.813 \\
\hline $1.643 \times 10^{-8}$ & $6.895 \times 10^{-5}$ & 41.97 & 0.878 \\
\hline $8.479 \times 10^{-4}$ & $3.774 \times 10^{-5}$ & $44 \cdot 51$ & 0.917 \\
\hline $8.234 \times 10^{-4}$ & $3.695 \times 10^{-5}$ & 44-87 & 0.924 \\
\hline $4 \cdot 128 \times 10^{-4}$ & $1.965 \times 10^{-5}$ & $47 \cdot 60$ & 0.969 \\
\hline $1.695 \times 10^{-4}$ & $8.362 \times 10^{-6}$ & $49 \cdot 33$ & 0.994 \\
\hline $8.247 \times 10^{-5}$ & $4.214 \times 10^{-1}$ & $51 \cdot 10$ & \\
\hline $1.649 \times 10^{-5}$ & $8.707 \times 10^{-7}$ & $52 \cdot 80$ & \\
\hline
\end{tabular}


Table 5. Conductance data at $45^{\circ} \mathrm{C}$

\begin{tabular}{|c|c|c|c|}
\hline $\begin{array}{l}C \\
\mathbf{M}\end{array}$ & 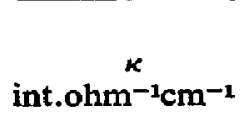 & $\underset{\substack{\Lambda \\
\text { int.ohm-1 } \\
\mathrm{mole}^{-1}}}{\mathrm{~cm}^{2}}$ & $\gamma$ \\
\hline $\begin{array}{l}5.295 \times 10^{-2} \\
4.235 \times 10^{-2} \\
2.122 \times 10^{-2} \\
1.696 \times 10^{-2} \\
1.019 \times 10^{-2} \\
8.169 \times 10^{-8} \\
6.539 \times 10^{-8} \\
4.226 \times 10^{-8} \\
3.272 \times 10^{-8} \\
1.640 \times 10^{-9} \\
8.444 \times 10^{-4} \\
8.200 \times 10^{-4} \\
4.110 \times 10^{-4} \\
1.688 \times 10^{-4} \\
8.213 \times 10^{-5} \\
1.643 \times 10^{-5}\end{array}$ & $\begin{array}{l}9.422 \times 10^{-4} \\
8.229 \times 10^{-4} \\
5.217 \times 10^{-4} \\
4.447 \times 10^{-4} \\
3.170 \times 10^{-4} \\
2.674 \times 10^{-4} \\
2.314 \times 10^{-4} \\
1.581 \times 10^{-4} \\
1.335 \times 10^{-4} \\
7.315 \times 10^{-5} \\
4.039 \times 10^{-5} \\
3.974 \times 10^{-5} \\
2.121 \times 10^{-5} \\
9.238 \times 10^{-6} \\
4.614 \times 10^{-4} \\
9.564 \times 10^{-7}\end{array}$ & $\begin{array}{l}17 \cdot 79 \\
19 \cdot 43 \\
24 \cdot 59 \\
26 \cdot 22 \\
31 \cdot 11 \\
32 \cdot 73 \\
35 \cdot 39 \\
37 \cdot 41 \\
40 \cdot 80 \\
44 \cdot 60 \\
47 \cdot 83 \\
48 \cdot 46 \\
51 \cdot 61 \\
54 \cdot 73 \\
56 \cdot 18 \\
58 \cdot 21\end{array}$ & $\begin{array}{l}0.416 \\
0.444 \\
0.529 \\
0.554 \\
0.638 \\
0.662 \\
0.709 \\
0.734 \\
0.794 \\
0.866 \\
0.896 \\
0.906 \\
0.953 \\
0.999\end{array}$ \\
\hline
\end{tabular}

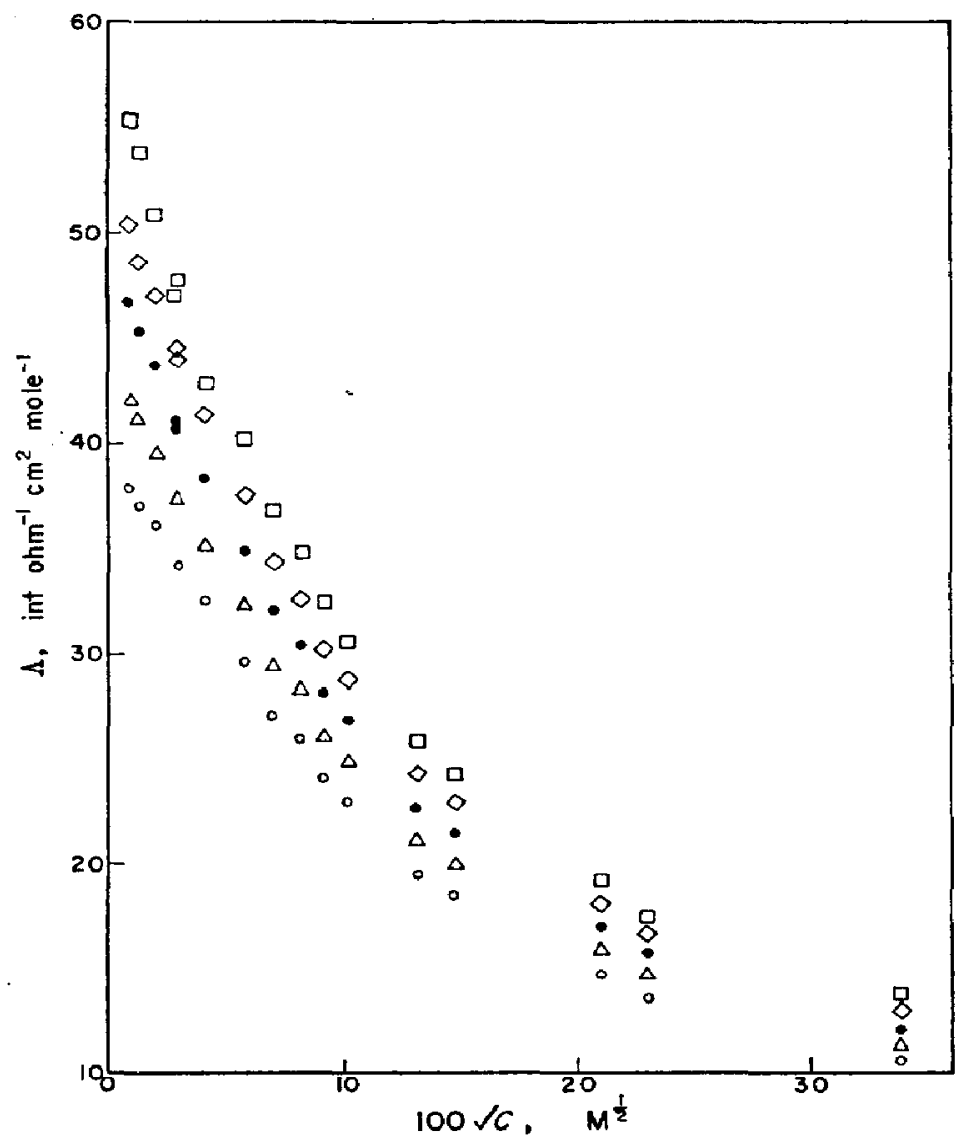

Fig. 1. Plot of the molar conductance $\Lambda$ vs $\sqrt{ } C$ at different temperatures. $0,25^{\circ} \mathrm{C} ; \triangle, 30^{\circ} \mathrm{C} ; 0,35^{\circ} \mathrm{C} ; \diamond, 40^{\circ} \mathrm{C} ; \square, 45^{\circ} \mathrm{C}$. 


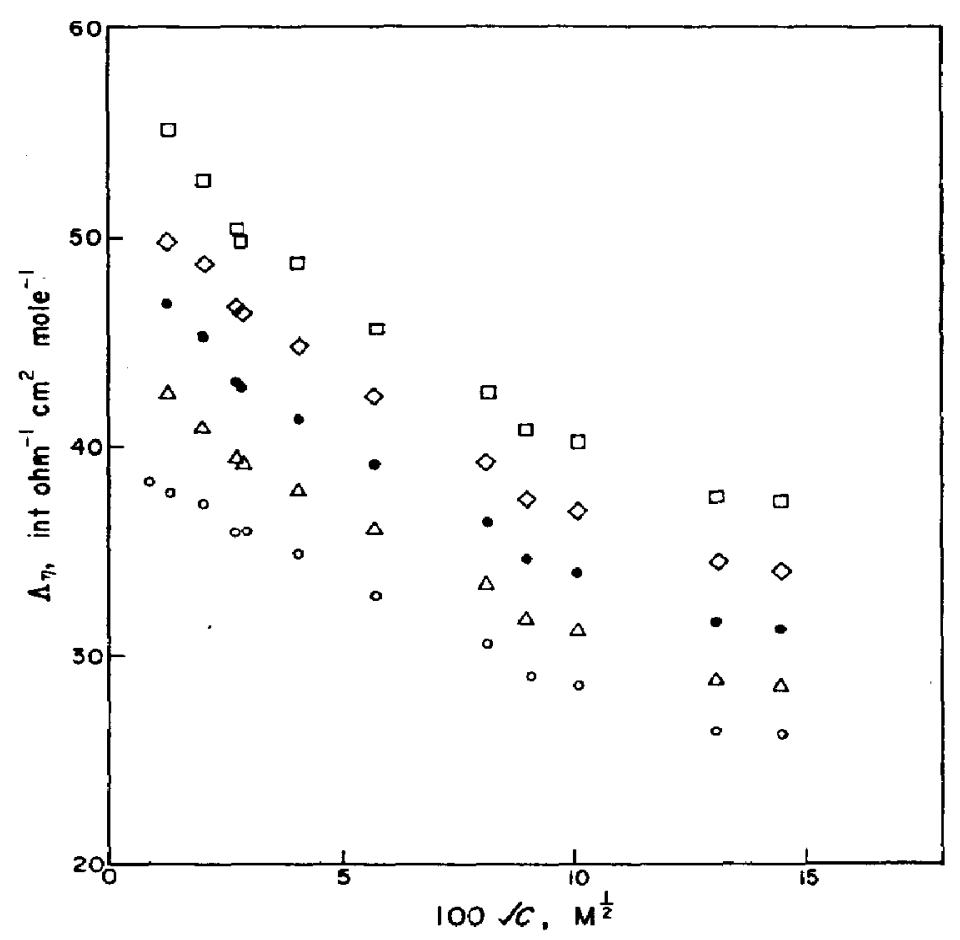

Fig. 2. Plot of $\Lambda^{\prime} \eta v s \sqrt{ } C$ at different temperatures.

$\Lambda_{\eta}{ }^{\prime}=\Lambda_{\eta}+S(C \gamma)^{1 / 2}-E C \gamma \log (C \gamma) .0,25^{\circ} \mathrm{C} ; \triangle, 30^{\circ} \mathrm{C} ; \bullet, 35^{\circ} \mathrm{C} ; \diamond, 40^{\circ} \mathrm{C}$;

$\square, 45^{\circ} \mathrm{C}$.

The meaning of each term is given in Fuoss' original paper. ${ }^{6}$ From (1), the equilibrium constant of the ionic association process, $K_{A}$, and the $J$ parameter, are determined. $J$ is directly related to $a$, the mean distance of nearest approach of the pairs of ions.

As already indicated, the evaluation is made by successive approximations. An initial value of $\Lambda_{0}$ calculated by Shedlovsky's equation is chosen. ${ }^{6}$ The procedure indicated by Fuoss is then followed until a set of $x, y$ values representing a straight line is found. If the plot bends downward, a new lower value is chosen, and the procedure repeated until necessary. If the plot bends upward, a higher value of $\Lambda_{0}$ is selected. The constants for using (1) at different temperatures are assembled in

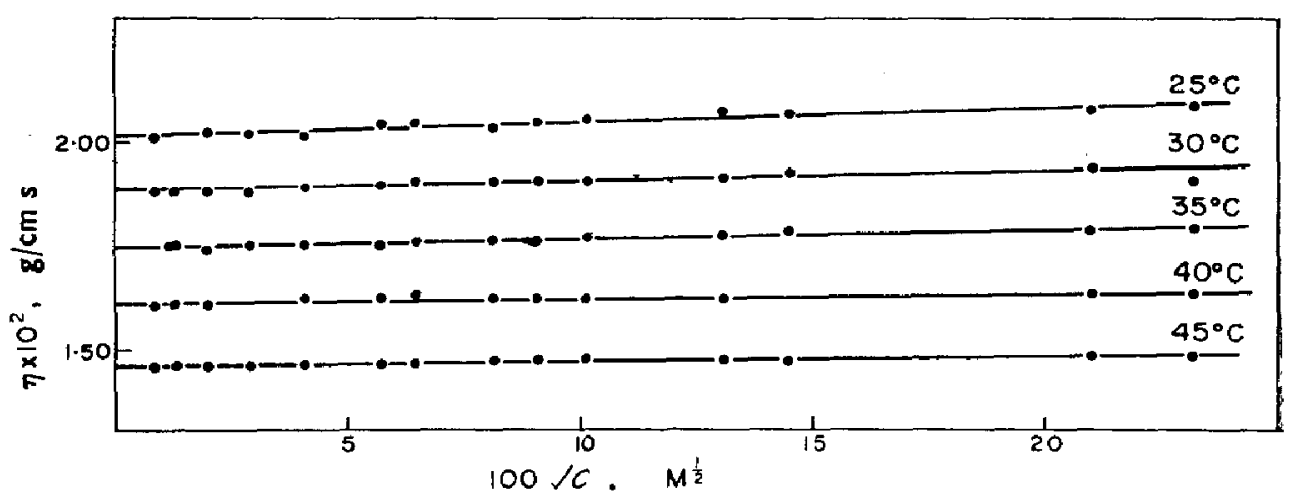

FIG. 3. Plot of the viscosity coefficient $\eta v s \sqrt{ } C$ at different temperatures. 
Tables 6 and 7. Table 7 also includes values of the dielectric constant of the solvent, $D$, the limiting molar conductance calculated with Shedlovsky's equation, and parameters obtained with (I).

From Table 7 two important facts are deduced. First, the dissociation constant decreases slightly with the temperature. This effect is similar to that observed for other 1-1 type electrolytes, such as acetic acid in water. ${ }^{8}$ By applying the Kirchhoff

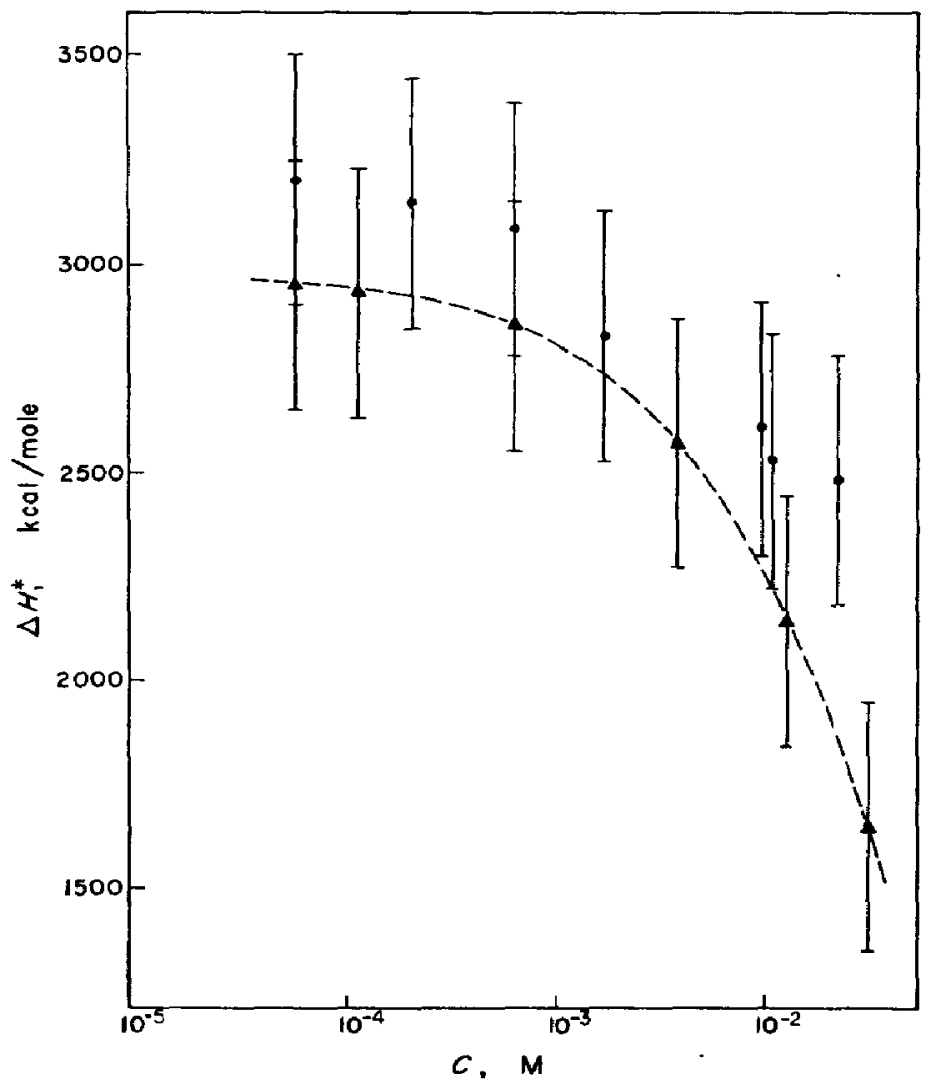

Fig. 4. Dependence of the experimental activation energy for conductance on concentration.

-, experimental values. $\Delta$, values calculated with equation (5).

equation the enthalpy change related to the ionic dissociation is obtained, $\Delta H_{\mathrm{d}}=$ $-(2 \pm 1) \mathrm{Kcal} / \mathrm{mole}$. This figure is significantly higher than $R T$. Secondly, conclusions about mean ionic radius are derived from the $J$ values. $J$ is defined by

$$
J=\sigma_{1} \Lambda_{0}+\sigma_{2}
$$

the expressions $\sigma_{1}$ and $\sigma_{2}$ are given in the literature. ${ }^{5}$ Table 7 shows that $J$ varies inversely with $D$ at constant temperature. From $J$, the mean ionic radius calculated for the range of temperature and concentration of the present work results, $a=$ $(2 \cdot 3 \pm 0 \cdot 3) \times 10^{-8} \mathrm{~cm}$, this figure being practically temperature-independent. The degree of dissociation, $\gamma$, shown in the Tables was also calculated with Fuoss' procedure. 


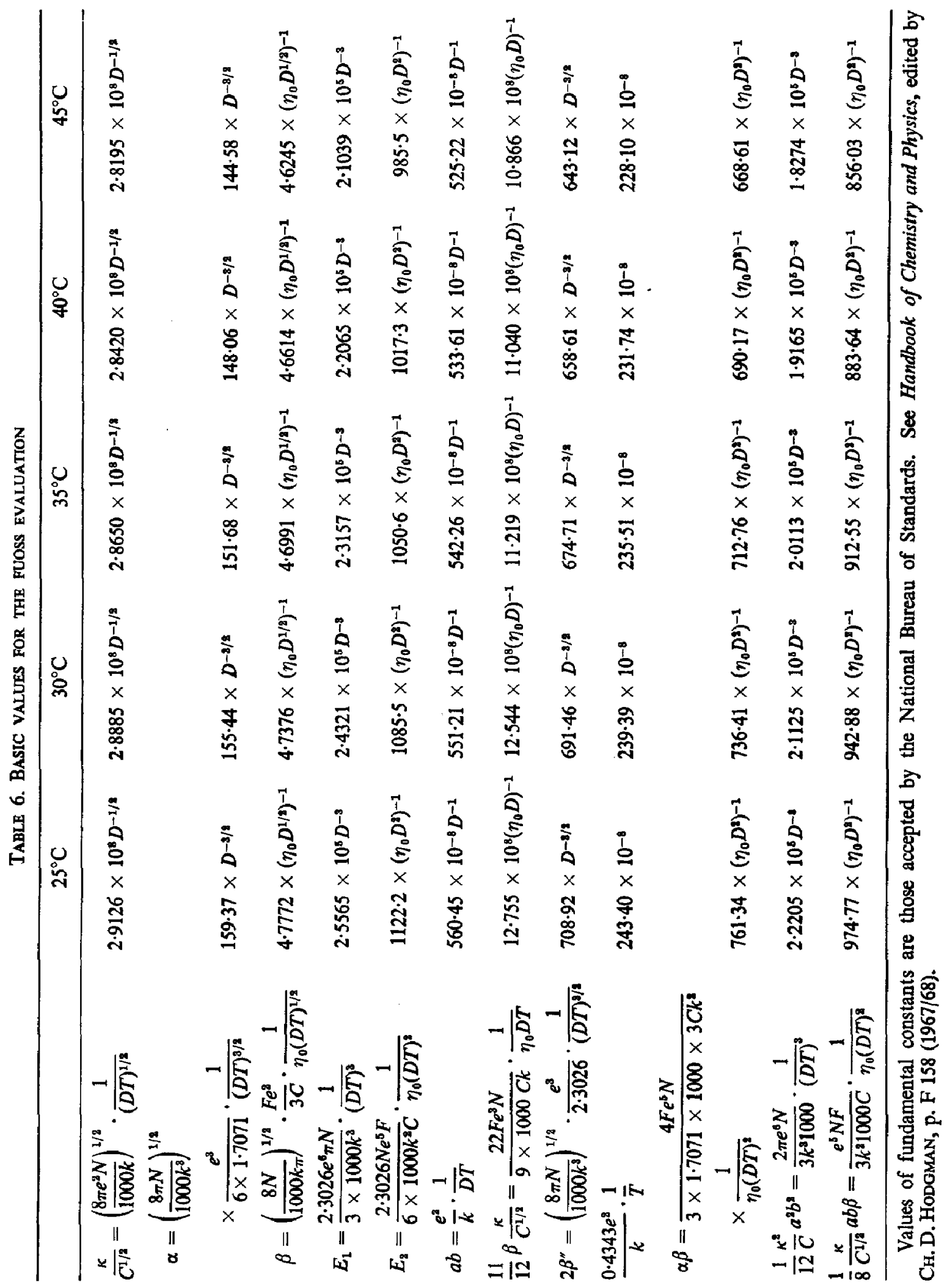


TABLE 7.

\begin{tabular}{|c|c|c|c|c|c|c|c|c|c|}
\hline${ }^{\circ} \mathrm{C}$ & $\Lambda_{0(8)}$ & $\Lambda_{0(\mathrm{~F})}$ & $D$ & $\eta_{0} \times 10^{2}$ & $\Lambda_{0(F)} \eta_{0}$ & $J$ & $\boldsymbol{K}_{\boldsymbol{\Delta}}$ & $K_{\mathrm{D}}$ & $E$ \\
\hline $\begin{array}{l}25 \\
30 \\
35 \\
40 \\
45\end{array}$ & $\begin{array}{l}38 \cdot 74 \\
43 \cdot 50 \\
47 \cdot 43 \\
51 \cdot 41 \\
55 \cdot 33\end{array}$ & $\begin{array}{l}38 \cdot 34 \\
41 \cdot 80 \\
46 \cdot 80 \\
50 \cdot 00 \\
55 \cdot 00\end{array}$ & $\begin{array}{l}46 \cdot 5 \\
44 \cdot 3 \\
42 \cdot 0 \\
39 \cdot 7 \\
37 \cdot 4\end{array}$ & $\begin{array}{l}2.015 \\
1.886 \\
1.746 \\
1.609 \\
1.460\end{array}$ & $\begin{array}{l}0.773 \\
0.788 \\
0.817 \\
0.804 \\
0.803\end{array}$ & $\begin{array}{l}160 \pm 20 \\
190 \pm 20 \\
240 \pm 20 \\
320 \pm 20 \\
360 \pm 20\end{array}$ & $\begin{array}{l}115 \cdot 7 \\
117 \cdot 0 \\
128 \cdot 0 \\
130 \cdot 2 \\
147 \cdot 2\end{array}$ & $\begin{array}{l}8 \cdot 64 \\
8 \cdot 55 \\
7 \cdot 81 \\
7 \cdot 68 \\
6 \cdot 79\end{array}$ & $\begin{array}{r}71 \cdot 67 \\
87 \cdot 48 \\
112 \cdot 05 \\
136 \cdot 21 \\
172 \cdot 93\end{array}$ \\
\hline
\end{tabular}

\section{The temperature coefficient}

The expression for the.molar conductance contains a number of terms depending on the temperature. In a general way, the molar conductance, corrected for the Falkenhagen-Dole viscosity factor, $\Lambda_{\eta}$, can be written ${ }^{\theta}$

$$
\Lambda_{\eta} \approx \Lambda=\Lambda\left(\Lambda_{0}, S, E, J, K_{\Delta}, C, \gamma, f\right) \text {. }
$$

As for simple inorganic salts $\Lambda_{\eta}$ and $\Lambda$ are nearly equal and depend practically in the same way on $T$, in order to obtain a temperature-dependent equation we write the following general equation to express the temperature dependence of molar conductance,

$$
\begin{aligned}
\frac{\mathrm{d} \ln \Lambda}{\mathrm{d}(1 / T)}= & \frac{1}{\Lambda}\left(\frac{\partial \Lambda}{\partial \Lambda_{0}} \frac{\mathrm{d} \Lambda_{0}}{\mathrm{~d}(1 / T)}+\frac{\partial \Lambda}{\partial S} \frac{\mathrm{d} S}{\mathrm{~d}(1 / T)}\right. \\
& +\frac{\partial \Lambda}{\partial E} \frac{\mathrm{d} E}{\mathrm{~d}(1 / T)}+\frac{\partial \Lambda}{\partial J} \frac{\mathrm{d} J}{\mathrm{~d}(1 / T)}+\frac{\partial \Lambda}{\partial K_{\Lambda}} \frac{\mathrm{d} K_{\mathrm{A}}}{\mathrm{d}(1 / T)} \\
& \left.+\frac{\partial \Lambda}{\partial C} \frac{\mathrm{d} C}{\mathrm{~d}(1 / T)}+\frac{\partial \Lambda}{\partial \gamma} \frac{\mathrm{d} \gamma}{\mathrm{d}(1 / T)}+\frac{\partial \Lambda}{\partial f} \frac{\mathrm{d} f}{\mathrm{~d}(1 / T)}\right)
\end{aligned}
$$

The partial derivatives are obtained from (1), assuming that the coefficient $\mathrm{d} C / \mathrm{d} T$ is negligible. Furthermore, as the product $\Lambda_{0} \eta_{0}$ is independent of $T$, the following expression is deduced for the activation energy of the molar conductance,

$$
\begin{aligned}
\Delta H_{\Lambda}^{*}= & -\Delta H_{\eta}{ }^{*}+\frac{R}{\Lambda} u^{1 / 2} S \frac{\mathrm{d} \ln S}{\mathrm{~d}(1 / T)}-\frac{R}{\Lambda} u \log u E \frac{\mathrm{d} \ln E}{\mathrm{~d}(1 / T)}-\frac{R}{\Lambda} u J \frac{\mathrm{d} \ln J}{\mathrm{~d}(1 / T)} \\
& +R u f^{2} K_{\mathrm{\Lambda}} \frac{\mathrm{d} \ln K_{\mathrm{A}}}{\mathrm{d}(1 / T)}+\frac{R}{\Lambda} \frac{S}{2} u^{1 / 2} \frac{\mathrm{d} \ln u}{\mathrm{~d}(1 / T)}-0.4343 \frac{R}{\Lambda} E u \frac{\mathrm{d} \ln u}{\mathrm{~d}(1 / T)} \\
& -\frac{R}{\Lambda} E u \log u \frac{\mathrm{d} \ln u}{\mathrm{~d}(1 / T)}-\frac{R}{\Lambda} J u \frac{\mathrm{d} \ln u}{\mathrm{~d}(1 / T)}+R f^{2} K_{\mathrm{\Delta}} u \frac{\mathrm{d} \ln u}{\mathrm{~d}(1 / T)} \\
& +2 R K_{\Delta} f^{2} u \frac{\mathrm{d} \ln f}{\mathrm{~d}(1 / T)},
\end{aligned}
$$

where $u=C \gamma$.

Equation (5) shows that the activation energy of the conduction process is practically equal in absolute value to the activation energy of the viscosity at infinite dilution. The terms involving $C$ in (5) are due to ionic interactions participating in the electrical conduction. They are mainly related to the dependence of the dielectric constant of the solvent and the association constant of the electrolyte with temperature. Summing 
TABle 8

\begin{tabular}{rrrrrr}
\hline${ }^{\circ} \mathrm{C}$ & $\frac{\mathrm{d} \ln \eta_{\mathrm{o}}}{\mathrm{d}(1 / T)}$ & $E \frac{\mathrm{d} \ln E}{\mathrm{~d}(1 / T)} \times 10^{-5}$ & $J \frac{\mathrm{d} \ln J}{\mathrm{~d}(1 / T)} \times 10^{-5}$ & $K_{\mathrm{A}} \frac{\mathrm{d} \ln K_{\mathrm{A}}}{\mathrm{d}(1 / T)} \times 10^{-6}$ & $S \frac{\mathrm{d} \ln S}{\mathrm{~d}(1 / T)} \times 10^{-5}$ \\
\hline 25 & 1510 & -2.96 & -6.80 & -1.30 & -1.14 \\
30 & 1510 & -3.61 & -8.08 & -1.31 & -1.28 \\
35 & 1510 & -4.63 & $-10-20$ & -1.43 & -1.42 \\
40 & 1510 & -5.63 & -13.60 & -1.46 & -1.59 \\
45 & 1510 & -7.14 & -15.30 & -1.65 & -1.82 \\
\hline
\end{tabular}

up these contributions, they tend to diminish $\Delta H_{\Lambda}{ }^{*}$ with respect to $\Delta H_{\eta}{ }^{*}$. This effect is illustrated in Fig. 4, although the scatter of the experimental results is somewhat pronounced. This fact does not encourage any further analysis of (5) but on the knowledge of $\mathrm{d} S / \mathrm{d}(1 / T), \mathrm{d} J / \mathrm{d}(1 / T), \mathrm{d} E / \mathrm{d}(1 / T), \mathrm{d} K_{\mathrm{A}} / \mathrm{d}(1 / T), \mathrm{d} u / \mathrm{d}(1 / T)$ and $\mathrm{d} f / \mathrm{d}(1 / T)$, previously calculated, the contribution of each term in that equation can be calculated and compared with experimental data. The dotted line in Fig. 4 corresponds to (5), which therefore explains quantitatively the experimental results reasonably well.

The non-coincidence of the activation energies for electrical conductance and viscosity over the whole range of concentrations is not surprising, as the mechanism of the two transport processes are not the same. As a matter of fact, ionic interactions predominate in the electrical conductance mechanism yielding a square root dependence of the conductance on concentration. On the other hand, the viscous process involves principally the participation of ion-solvent interactions. Thus, the dependence of the viscosity coefficient is mainly governed by terms that depend linearly on the concentration, in equations such as the Jones-Dole equation for the viscosity of ionic solutions. ${ }^{10}$

Acknowledgement-This work has been supported in part by the Consejo Nacional de Investigaciones Cientlficas y Técnicas of Argentina.

\section{REFERENCES}

1. J. A. Olabe, M. C. Giordano and A. J. Arví, Electrochim. Acta 12, 907 (1967).

2. J. A. Bolzan and A. J. Arvta, Electrochim. Acta 15, 39 (1970).

3. P. G. Sears, G. R. Lester and L. R. Dawson, J. phys. Chem. 60, 1433 (1966).

4. J. A. Bolzan, M. C. Giordano and A. J. Arvia, Anal. Asoc. Quim. Arg. 54, 171 (1966).

S. R. M. Fuoss, J. Am. chem. Soc. 81, 2659 (1959).

6. R. M. Fuoss and T. ShedLovsky, J. Am. chem. Soc. 71, 1496 (1949).

7. Y. Doucet, F. Calmes-Perrault and M. T. Durand, C.r. hebd. Séanc. Acad. Sci., Paris, 260, 1878 (1965).

8. M. Dole, Experimental and Theoretical Electrochemistry, Chapter V. McGraw-Hill, New York (1935).

9. R. M. Fuoss, J. Am. chem. Soc. 56, 1857 (1934).

10. R. H. Stokes and R. Mills, Viscosity of Electrolytes and Related Properties, p. 22. Pergamon Press, Oxford (1965). 